\title{
The Role of the Striatum in Processing Language Rules: Evidence from Word Perception in Huntington's Disease
}

\author{
Marc Teichmann ${ }^{1,2,3}$, Emmanuel Dupoux ${ }^{2}$, Sid Kouider ${ }^{2}$, \\ and Anne-Catherine Bachoud-Lévi ${ }^{1,3}$
}

\begin{abstract}
On the assumption that linguistic faculties reflect both lexical storage in the temporal cortex and combinatorial rules in the striatal circuits, several authors have shown that striataldamaged patients are impaired with conjugation rules while retaining lexical knowledge of irregular verbs [Teichmann, M., Dupoux, E., Kouider, S., Brugières, P., Boissé, M. F., Baudic, S., Cesaro, P., Peschanski, M., \& Bachoud-Lévi, A. C. (2005). The role of the striatum in rule application. The model of Huntington's disease at early stage. Brain, 128, 1155-1167; Ullman, M. T., Corkin, S., Coppola, M., Hickok, G., Growdon, J. H., Koroshetz, W. J., \& Pinker, S. (1997). A neural dissociation within language: Evidence that the mental dictionary is part of declarative memory, and that grammatical rules are processed by the procedural system. Journal of Cognitive Neuroscience, 9, 266-276]. Yet, such impairment was documented only with explicit conjugation tasks in the production domain. Little is known about whether it generalizes to other language modalities such as perception and whether it refers to implicit language processing or rather to intentional rule operations through executive
\end{abstract}

\section{INTRODUCTION}

There is now a wide consensus that the striatum is involved in language processing (see Lieberman, 2001, for a review). However, its specific role and the way it impacts linguistic processes remain largely unclear. Neuropsychological studies that assessed striatal-damaged patients provided heterogeneous and even contradictory results. Vascular disorders involving the striatum have been linked to various patterns of aphasia (e.g., Kumral, Evyapan, \& Balkir, 1999) and degenerative disorders (Huntington's disease [HD], Parkinson's disease [PD]) have revealed linguistic troubles ranging from syntactic impairment (Illes, 1989) to disorganization of semantic

\footnotetext{
${ }^{1}$ INSERM U421, Equipe Avenir "Neuropsychologie interventionnelle", IM3/Paris XII, Créteil-ENS, Paris, France, ${ }^{2}$ EHESSENS-CNRS UMR8554, Laboratoire de Sciences Cognitives et Psycholinguistique, Paris, France, ${ }^{3} \mathrm{CHU}$ Henri Mondor, Neurology Department, AP-HP, Créteil, France
}

functions. We investigated these issues by assessing perceptive processing of conjugated verb forms in a model of striatal dysfunction, namely, in Huntington's Disease (HD) at early stages. Rule application and lexical processes were evaluated in an explicit task (acceptability judgments on verb and nonword forms) and in an implicit task (lexical decision on frequencymanipulated verb forms). HD patients were also assessed in executive functions, and striatal atrophy was evaluated with magnetic resonance imaging (bicaudate ratio). Results from both tasks showed that HD patients were selectively impaired for rule application but lexical abilities were spared. Bicaudate ratios correlated with rule scores on both tasks, whereas executive parameters only correlated with scores on the explicit task. We argue that the striatum has a core function in linguistic rule application generalizing to perceptive aspects of morphological operations and pertaining to implicit language processes. In addition, we suggest that the striatum may enclose computational circuits that underpin explicit manipulation of regularities. knowledge (Smith, Butters, White, Lyon, \& Granholm, 1988). Yet, two conflicting views have emerged. On the one hand, it has been argued that the striatum is involved in lexico-semantic processes (Copland, 2003; Wallesch \& Papagno, 1988; Crosson, 1985) while, on the other hand, the striatum has been claimed to impact grammatical computations (Friederici \& Kotz, 2003; Moro et al., 2001; Ullman, 2001). This latter view has been largely developed by Ullman (2001), who proposes that the striatum subserves the concatenation of stored lexical information through the application of grammatical rules.

The Ullman hypothesis is tied to psycholinguistic models that divide language processing into two components: a mental lexicon and a computational grammar (e.g., Pinker, 1999; Chomsky, 1965). The mental lexicon is the repository of all idiosyncrasies, containing phonological, morphological, and syntactic specification of morphemes, words, or even whole sentences as in idioms. The computational grammar contains rules that 
can be applied in a combinatorial and recursive fashion. Ullman (2001) proposed an anatomic correlate of this lexicon/rule dichotomy, stating that lexical storage depends on a declarative memory system that relates to temporal-cortical structures, whereas rule application depends on an implicit, procedural system that relates to fronto-striatal circuits. In order to test the Ullman hypothesis, language research has mostly focused on inflectional morphology; a language domain which was initially used by psycholinguists contrasting the conjugation of irregular and regular verbs (see Clahsen, 1999, for a review). Regular forms (e.g., walk-walked) and irregular forms (e.g., go-went) are equivalent in syntactic (tensed, verb) and semantic dimensions but differ in that their form is predictable in the former case (root + -ed) and idiosyncratic in the latter. Hence, irregular forms are claimed to be stored in the mental lexicon, whereas regular forms depend on rule-defined computation of their morphemic constituents (e.g., walk and $-e d$ ), which are assumed to be separately stored in the lexicon (see Pinker, 1999, for a review). Note that the lexicon/rule hypothesis does not hold that regular forms are never stored in the lexicon, but simply that they do not have to be (see Pinker \& Ullman, 2002, for a review). In particular, it has been posited that full-form storage for regulars can occur under certain conditions, such as processing of high-frequency forms. By contrast, lowfrequency regulars are claimed to be necessarily subjected to rule computation (Pinker \& Ullman, 2002; Schreuder \& Baayen, 1995).

Ullman, Corkin, et al. (1997) used this regular/irregular contrast in patients with striatal damage (HD and PD) and with temporal lesions (Alzheimer's disease $[\mathrm{AD}]$ ). Patients were asked to perform an elicitation task in which they had to produce the past-tense form upon presentation of the present-tense form (e.g., "Everyday, I walk in the park. Just like everyday, yesterday I__ in the park"). In addition, the authors also used novel verbs (e.g., to plag) because novel verbs (NV) have no lexical representation, and thus, necessarily depend on rule application (plag-plaged). They found that striataldamaged patients were impaired on rule application but not on lexical knowledge: PD patients suffixed regular and NV incorrectly (e.g., "jump-id"; "plag-id"), and HD patients tended to overapply the suffixation rule (e.g. "jump-ed-ed"). Conversely, AD patients were selectively impaired with lexical knowledge (e.g. "dag" instead of "dug"). However, these results are questionable because regular and irregular past-tense forms were not fully matched on frequency, and HD patients did not display a significant difference between regulars, irregulars, and NV. Longworth, Keenan, Barker, MarslenWilson, and Tyler (2005) replicated the Ullman task with HD and PD patients by using frequency-matched verb materials and did not find the expected performance difference neither between irregulars and regulars nor between irregulars and NV. This shed some doubt on the striatum-rule hypothesis. Yet, neither Ullman's nor Longworth's study controlled for evolution stage in their patients, although neurodegenerative diseases such as HD progress, beyond the striatum, towards various cortical structures (e.g., Vonsattel et al., 1985). In HD, neuronal dysfunction and death originates in the caudate head and the putamen (see Peschanski, Cesaro, \& Hantraye, 1995, for a review), and thus, only early stages of the disease represent a reliable model of nearexclusive striatal disorders (Kuhl et al., 1982). Hence, Teichmann et al. (2005) assessed morphological processing in the early stages of French-speaking HD patients (Stages I and II according to Shoulson, 1981). In addition, French has the advantage of providing a richer inflectional system than English, which allows the exploration of a wider range of regularities. French verbs are organized into three basic morphological classes called conjugation groups. The major class is Conjugation 1, which contains regular verbs with infinitives ending in -er (e.g., aimer, donner... [to love, to give...]). This is the most productive class that is fully regular (e.g., future tense: aimera, donnera [will love, will give]). Conjugation 2 is formed by verbs that have an infinitive in -ir (such as finir, fournir... [to finish, to furnish...]), to which we will refer as to subregular verbs. Conjugation 2 is a smaller class than Conjugation 1 and it is less productive: Only about $70 \%$ of the verbs ending in -ir follow the same suffixation pattern (e.g., future tense: finira, fournira [will finish, will furnish]), whereas the remaining 30\% are unpredictable and belong to the third class. Conjugation 3 contains irregular verbs that have fully idiosyncratic inflections (e.g., venir-viendra, avoiraura... [come-will come, have-will have...]) as well as some verb clusters that respond to subregularities (e.g., $26 \%$ of the verbs ending in "-oir" share the same conjugation pattern in the future tense). We will refer to them as irregular verbs only when their conjugation is either fully idiosyncratic or when they belong to verb clusters with a productivity smaller than $30 \%$. Teichmann et al. exploited these distinctions by using $\mathrm{NV}$ ending in -er (regular NV; e.g., garouster) and in -ir (subregular NV; e.g., saurentir) to assess the fully productive default rule and less productive subrules. Although one may argue that verbs ending in -ir are stored in the lexicon because of the relatively high number of exceptions, the results of the study indicated that they are subjected to rule application and that these rules are impaired in HD. First, controls systematically applied the same suffixation pattern to subregular NV, suggesting that subregularities trigger rule-defined processing. Second, HD patients' performance was massively impaired with subregular NV, whereas it was largely spared with irregular verbs, regular verbs, and regular NV. Furthermore, impairment with subregular NV in HD corresponded mainly to overregularizations, suggesting that subrule impairment is compensated by the use of the default rule. Thus, the authors concluded that 
striatal dysfunction does yield rule disorders, which are, however, restricted to the computations of relatively unproductive rules. Indeed, because subrules are less frequent, less productive, and thus, less automatized than the default rule, the authors assumed that their computation is more sensitive even to slight disorders in its neural substrate.

In sum, despite the various investigations in the domain of inflectional morphology, the issue of striatal involvement in linguistic rule application remains highly controversial. A plausible reason for the relative inconsistency of the previous studies is that striatal-damaged patients also suffer from problems of speech articulation, which makes it difficult to interpret the results of production studies. Thus, a key issue is to retest the striatum-rule hypothesis in language perception rather than in language production. Because morphological rules specify the processing of morphemic constituents, they are assumed to define both the combination of roots and suffixes in speech production and their decomposition in speech perception (MacKay, 1978). Yet, evidence for striatal involvement in rule application during language perception has only been suggested in the domains of syntax (Teichmann et al., 2005; Friederici, Ruschemeyer, Hahne, \& Fiebach, 2003; Ni et al., 2002; Moro et al., 2001) and phonology (Tettamanti et al., 2005), and it is thus difficult to decide whether the striatum merely underpins a production-specific assemblage of morphemic language chunks or whether it genuinely operates rules as such. Experiment 1 was aimed at addressing these issues by assessing acceptability judgments during the auditory perception of verbs and novel verbs. Under the hypothesis that striatal-damaged patients have rule disorders, we expected them to express with NV, and especially with subregular forms. Furthermore, we hypothesized that striatal-damaged patients compensate for rule impairment by accessing frequent forms of existing regular and subregular verbs flawlessly in the mental lexicon.

The second issue of the present research was to specify whether the striatum operates morphological rules through implicit language processes or rather through intentional extraction of regularities. Assessing patients through explicit manipulation tasks (conjugation of verbs and NV) has the disadvantage of involving intentional response strategies such as conscious extraction and manipulation of suffixation regularities. Given that intentional rule manipulation has been linked to executive functions (Ashby \& Waldron, 1999), and given that executive functions are deficient in striatal-damaged patients (e.g., Brown, Schneider, \& Lidsky, 1997), it remains difficult to know whether the striatum is merely involved in executive generated rule manipulations or in implicit language computations as well. In order to minimize intentional response strategies, psycholinguistic research on morphological processing has used implicit processing manipulations. One such manipula- tion is the word frequency effect by which rule-defined decomposition of suffixed words has been related to automatic processing within the language module (see e.g., Taft, 1979). Clahsen, Eisenbeiss, and Sonnenstuhl (1997), using a lexical decision task (word vs. nonword decision), have shown that reaction times (RTs) with irregular verbs depend on form frequency, reflecting that conjugated forms of irregulars are accessed in the mental lexicon, whereas RT with regulars do not. Conversely, it has been shown that RTs with regular verb forms depend on the frequency of their root, reflecting that roots of regulars (and not conjugated forms) are accessed in the mental lexicon and that morphemic decomposition is primarily involved (Bertram et al., 2000). We posit that using similar tasks with striataldamaged patients will clarify whether rule-based processes generated by the striatum are genuinely related to implicit and language-specific operations. In particular, we hypothesized that RT represents a sufficiently sensitive measure to show that striatal-damaged patients access frequent regular and subregular verbs directly in the mental lexicon instead of applying rules to them. Thus, we expected these patients to yield a form frequency effect for frequent regular and subregular forms as well as for irregulars. This issue will be addressed in Experiment 2 where we used a lexical decision task while manipulating form frequency and root frequency in regular, subregular, and irregular verbs.

Both experiments were run with HD patients that were in the early stages of the disease. We predicted them to suffer from selective rule disorders that should express in both the explicit (Experiment 1) and the implicit tasks (Experiment 2). Moreover, in order to further investigate the interdependence between linguistic rule application and the striatum, as well as between rule application and executive functions, we realized different correlation analyses: Rule performance was respectively correlated with magnetic resonance imaging (MRI) measures of striatal atrophy by using bicaudate ratios and with the Unified Huntington's Disease Rating Scale (UHDRS; Huntington Study Group, 1996), which contains motor, functional capacity, and executive functions subscales. In addition, global intellectual capacities were assessed with the Mattis Dementia Rating Scale (MDRS; Mattis, 1976).

\section{METHODS}

\section{Participants}

Fifteen patients with HD at Stage I, according to the "Total Functional Capacity scale" (Shoulson, 1981), and 15 healthy volunteers participated in this study. HD patients were recruited in the out-clinic patients within the follow-up program of interventional therapy that was approved by the ethics committee of the Henri Mondor Hospital. HD patients had no previous neurological or 
psychiatric history other than $\mathrm{HD}$, and neurological diagnosis was genetically confirmed. Healthy controls had no neurological or psychiatric disorders and were paired to the HD patients according to their age and educational level (all $F \mathrm{~s}<1$ ). All participants gave informed consent. Demographic data are summarized in Table 1.

\section{General Assessment}

All patients were evaluated using the UHDRS (Huntington Study Group, 1996) and the MDRS (Mattis, 1976). Furthermore, atrophy of the caudate was assessed in 10 patients with MRI by measuring the bicaudate ratio (i.e., the minimal distance between the caudate indentations of the frontal horns divided by the distance between the inner tables of the skull along the same line, multiplied by 100). Data are summarized in Table 2 .

\section{Experiment 1: Acceptability Judgment of Conjugated Verb and NV Forms}

In this experiment, participants made explicit right/ wrong judgments on auditorily presented verb and NV forms. Lexical competencies were tested with irregular verb forms (e.g., aller-ira [come-will come]), whereas rule application was probed for with regular NV (e.g., froucher) and with subregular NV (e.g., rinir). For each stimulus, we presented correct forms and different forms with inappropriate suffixes. By analogy to production errors in HD (Teichmann et al., 2005), the error forms corresponded either to excessive use of the default rule (overregularizations, double suffixations) or of the subrule (subregularizations) or to the use of nonexisting suffixes (aberrant suffixations) (see Table 3).

We expected HD patients to show selective problems with NV that should mostly relate to subregular NV, whereas performance with irregular verbs was predicted to be spared. In addition, we also tested frequent regular and subregular forms of existing verbs (mean frequency 54 per million) under the hypothesis that HD patients circumvent impaired rule application by recovering

Table 1. Demographic Data of HD Patients and Controls

\begin{tabular}{lll}
\hline & \multicolumn{1}{c}{$H D$} & Controls \\
\hline$n$ & 15 & 15 \\
Sex & $9 \mathrm{~F} / 6 \mathrm{M}$ & $10 \mathrm{~F} / 5 \mathrm{M}$ \\
Age (years) & $46.9 \pm 9.8$ & $45.1 \pm 8.9$ \\
Educational level (years) & $13.3 \pm 3$ & $13.9 \pm 2$ \\
Laterality & $14 \mathrm{R} / 1 \mathrm{~L}$ & $15 \mathrm{R} / 0 \mathrm{~L}$ \\
Evolution duration (years) & $3.7 \pm 2.7$ & \\
CAG repeats & $44.5 \pm 3.9$ & \\
\hline
\end{tabular}

Table 2. Clinical Performance and Bicaudate Ratios of Patients

\begin{tabular}{|c|c|c|}
\hline & $\begin{array}{c}H D \\
(n=15)\end{array}$ & $\begin{array}{c}\text { Normal } \\
\text { Published Range }\end{array}$ \\
\hline $\begin{array}{l}\text { Total Functional Capacity } \\
\text { (TFC) }\end{array}$ & $12 \pm 1$ & 13 \\
\hline UHDRS Motor Score & $23.1 \pm 16.5$ & 0 \\
\hline Stroop color/words & $33.5 \pm 9.6$ & $>35^{\mathrm{a}}$ \\
\hline Fluency "PRV" in 2 min & $49.3 \pm 20.5$ & $>56^{\mathrm{b}}$ \\
\hline Symbol Digit Code & $35.6 \pm 10.5$ & $37^{\mathrm{c}}$ \\
\hline MDRS & $133.3 \pm 7.6$ & $>136$ \\
\hline Bicaudate ratio $^{e}$ & $18.2 \pm 4.2$ & $<10^{\mathrm{d}}$ \\
\hline \multicolumn{3}{|c|}{ a Norms are issued from Golden, 1978.} \\
\hline \multicolumn{3}{|c|}{ bardebat, Doyon, Puel, Goulet, and Joanett (1990). } \\
\hline \multicolumn{3}{|l|}{ 'Wechsler, 1981.} \\
\hline \multicolumn{3}{|l|}{ do Strakstein et al., 1989.} \\
\hline
\end{tabular}

them, without difficulties, directly in the mental lexicon like irregular forms.

Each of the five experimental conditions (irregular verbs, regular verbs, subregular verbs, regular NV, subregular NV) contained 21 stimuli except irregular verbs $(n=27)$. The verb stimuli were constructed from the roots of three irregular, three regular, and three subregular verbs. NV stimuli were constructed by changing two phonemes of three regular verb roots (regular NV) and of three subregular verb roots (subregular NV). Each root was tensed in present and future tense (third person, singular) yielding two correct and five error forms except for irregular verbs (seven error forms). Error forms were constructed by appending incorrect suffixes to the verb and $\mathrm{NV}$ roots yielding four distinct error types: (1) overregularizations (er-pattern suffixation instead of ir-pattern suffixation; e.g., finir-finera instead of finira), (2) subregularizations (ir-pattern suffixation instead of er-pattern suffixation; e.g., arriverarrivira instead of arrivera), (3) double suffixations [excessive appending of the regular -era suffix knowing that infinitives are readily suffixed in French; e.g., arriver-arriver-era or finir-finir-era (only future tense forms)], and (4) aberrant suffixations (nonexistent French suffixes were appended to the verb root; e.g., arriver-arrivedra). All NV stimuli consisted of phonotactically legal phoneme strings. The stimuli lists of the five experimental conditions were matched for number of syllables and phonemes (all $F$ S $<1$ ). Correct irregular, regular, and subregular groups were broadly matched for frequency $[F(2,15)=2,9, p=.09]$ according to the LEXIQUE 2 database (New, Pallier, Brysbaert, \& Ferrand, 2004). Indeed, the principal selection criterion was to use only frequent, that is, well-known, words from each 
Table 3. Correct and Error Forms Comprising Aberrant Suffixations (Aberrant), Overregularizations (Overreg), Subregularizations (Subreg), and Double Suffixations (Double Suff)

\begin{tabular}{|c|c|c|c|c|c|c|c|c|c|}
\hline \multirow[b]{2}{*}{ Verb Category } & \multirow[b]{2}{*}{$n$} & & \multirow[b]{2}{*}{$\begin{array}{c}\text { Correct } \\
(n=30)\end{array}$} & \multicolumn{4}{|c|}{ Correct and Error Forms (Third Person Singular) } & \multirow[b]{2}{*}{$n$} & \multirow[b]{2}{*}{$\begin{array}{c}\text { Form } \\
\text { Frequency }\end{array}$} \\
\hline & & & & $\begin{array}{l}\text { Aberrant } \\
(n=30)\end{array}$ & $\begin{array}{c}\text { Overreg } \\
(n=18)\end{array}$ & $\begin{array}{c}\text { Subreg } \\
(n=18)\end{array}$ & $\begin{array}{c}\text { Double Suff } \\
(n=15)\end{array}$ & & \\
\hline Irregular verbs & 3 & PRESENT & il vient & venosse & Vene & venit & $\|/ / / /\|$ & 27 & $\begin{array}{l}173 \pm 222 \\
\text { per million }\end{array}$ \\
\hline Venir (to come) & & FUTURE & il viendra & venidra & Venera & venira & venirera & & \\
\hline Regular verbs & 3 & PRESENT & il donne & donosse & $\mid / I / I / I /$ & donnit & $|/| / / I / I / I$ & 21 & $\begin{array}{l}94 \pm 93 \\
\text { per million }\end{array}$ \\
\hline donner (to give) & & FUTURE & il donnera & donnedra & /I//I/I/ & donnira & donnerera & & \\
\hline Subregular verbs & 3 & PRESENT & il finit & finosse & Fine & $\mid / I / I / I / I$ & $\| / I / I / /$ & 21 & $\begin{array}{l}16 \pm 17 \\
\text { per million }\end{array}$ \\
\hline finir (to finish) & & FUTURE & il finira & finidra & Finera & $/ / / / / / / / / /$ & finirera & & \\
\hline Regular NV & 3 & PRESENT & il frouche & frouchosse & $/ / / / / / / / /$ & frouchit & $/ / / / / / / / / /$ & 21 & \\
\hline Froucher & & FUTURE & il frouchera & frouchedra & $/ / / / / / / / / /$ & frouchira & froucherera & & $\mid / / / / / / / / / / /$ \\
\hline Subregular NV & 3 & PRESENT & il pichit & pichosse & Piche & $/ / / / / / / / /$ & /I/I/I/I/I/ & 21 & \\
\hline pichir & & FUTURE & il pichira & pichidra & Pichera & $/ / / / / / / / / /$ & pichirera & & /IIIIIIIIIIIII \\
\hline
\end{tabular}

Suffixes: "-e" (present) and "-era" (future) refer to the conjugation of regular verbs ending in "-er." "-it" (present) and "-ira" (future) refer to the conjugation of regular verbs ending in "-ir." Suffixes of "aberrant suffixations" do not exist in French conjugation. Several conjugated forms cannot exist (hatched fields), such as double suffixations of present tense forms (the present tense suffix is phonologically silent), overregularizations of regular verbs, and subregularizations of subregular verbs.

verb class; hence, irregular verbs totally matched with subregulars were too rare to be acceptable.

Participants were first tested with NV, then with verbs. The stimuli were presented at random to each participant. For each item, we orally presented the infinitive form (e.g., "Here is the nonexisting verb froucher") followed by a small carrier sentence that contained the conjugated form: "Aujourd'hui, il frouche" ["Today, he frouch-e"] for present tense and "Demain, il frouchera" ["Tomorrow, he frouch-era"] for future tense. Participants were instructed to make right/wrong judgments about the conjugated forms. Responses were considered as incorrect when participants accepted error forms or when they rejected correct forms.

\section{Experiment 2: Lexical Decision Task}

In order to assess implicit aspects of morphological processing, we used a speeded lexical decision task with visually presented verb forms (word vs. nonword decision). For normal participants, we assumed that conjugated irregular forms are directly recovered from the mental lexicon, whereas regular and subregular forms are subjected to rule-defined root-suffix decomposition with roots being subsequently recovered from the lexicon. Knowing that high-frequency items are more rapidly recovered than low-frequency items (see Balota, 1994, for a review), we varied either surface frequency (frequency of the conjugated form) or root frequency (summed frequency of the conjugated variants for a given verb). With respect to RT, we thus reasoned that surface frequency impacts the processing speed with irregular verbs, whereas root frequency impacts the processing speed with regular and subregular verbs. In HD, we expected that patients access frequent regular and subregular verbs directly in the lexicon instead of applying rules to them. Thus, surface frequency effects should be present for these forms as well as for irregular verbs. With respect to performance accuracy, we furthermore expected that low-frequency regular and subregular forms that depend necessarily on rule application (see Schreuder \& Baayen, 1995) should yield worse performance than high-frequency forms.

These issues were tested using three experimental subsets of stimuli (see Table 4). The first subset (I-R) compared the processing of irregular and regular forms. In both verb types, we varied surface frequency (high and low) while holding root frequency ${ }^{1}$ constant (yielding four stimuli lists). In HD, we predicted faster RT with high than with low surface frequency regulars while they were assumed to be similar in controls. In the second subset (R-R), we explored the processing of regular verbs using three stimuli lists to compare (i) high and low surface frequency forms (List 1 and List 2, respectively) that were matched for root frequency (high root frequency) and (ii) high and low root frequency forms (List 2 and List 3, respectively) that were matched for surface frequency (low surface frequency). As in the I-R 
Table 4. Composition of the Three Experimental Subsets of Experiment 2 (I-R, R-R and sR-sR)

\begin{tabular}{|c|c|c|c|c|c|c|c|}
\hline \multirow{2}{*}{$\frac{\text { Subset }}{\mathrm{I}-\mathrm{R}}$} & \multirow{2}{*}{$\begin{array}{l}\text { Verb Type } \\
\text { Regulars }\end{array}$} & \multirow{2}{*}{$\frac{\text { List }}{\text { List } 1}$} & \multicolumn{2}{|c|}{ Surface Frequency (Per Million) } & \multicolumn{2}{|c|}{ Root Frequency (Per Million) } & \multirow{2}{*}{$\frac{n}{9}$} \\
\hline & & & High & $1.6 \pm 0.4$ & \multicolumn{2}{|c|}{$122 \pm 19$} & \\
\hline & & List 2 & Low & $0.3 \pm 0.1$ & \multicolumn{2}{|c|}{$123 \pm 15$} & 9 \\
\hline & Irregulars & List 3 & High & $1.9 \pm 0.3$ & \multicolumn{2}{|c|}{$150 \pm 47$} & 6 \\
\hline & & List 4 & Low & $0.5 \pm 0.4$ & \multicolumn{2}{|c|}{$109 \pm 61$} & 7 \\
\hline \multirow[t]{3}{*}{$\mathrm{R}-\mathrm{R}$} & \multirow[t]{3}{*}{ Regulars } & List 1 & High & $1.6 \pm 0.4$ & High & $107 \pm 17$ & 10 \\
\hline & & List 2 & Low & $0.1 \pm 0.04$ & High & $102 \pm 8$ & 10 \\
\hline & & List 3 & Low & $0.1 \pm 0.05$ & Low & $7 \pm 1$ & 10 \\
\hline \multirow[t]{3}{*}{$s R-s R$} & \multirow[t]{3}{*}{ Subregulars } & List 1 & High & $0.3 \pm 0.1$ & High & $24 \pm 8$ & 9 \\
\hline & & List 2 & Low & $0.05 \pm 0.02$ & High & $20 \pm 4$ & 9 \\
\hline & & List 3 & Low & $0.04 \pm 0.01$ & Low & $3 \pm 1$ & 9 \\
\hline
\end{tabular}

For each subset, surface frequencies and root frequencies that are represented in grayed fields are matched on their decimal algorithms. Furthermore, in the I-R subset, List 1 and List 3, as well as List 2 and List 4, were matched for their respective surface frequencies. In the R-R and the sR-sR subsets, surface frequencies between Lists 1 and 2 varied by the same factor as varied root frequencies between Lists 2 and 3 .

subset, we predicted that HD patients have faster RT for high than for low surface frequency regulars (List 1 and List 2). Furthermore, we expected that low surface regulars still yield root frequency effects because they were assumed to have no full-form representations (List 2 and List 3). In the third subset (sR-sR), we assessed the same contrasts as for the R-R subset but with subregular verbs. The predictions were the same as in the $\mathrm{R}-\mathrm{R}$ subset.

The experimental materials comprised a total of 81 conjugated verb forms (future tense, third person singular) of French irregular, regular, and subregular verbs. For each of the 81 verb forms (the $I-R$ and the $R-R$ subset shared seven verb stimuli), a nonword was derived by changing two letters of the root while verifying that nonwords did not have any orthographic neighbor. This resulted in 81 additional stimuli. Forty filler words (nouns and adjectives) were added to vary the material and minimize strategic biases to the maximum. Another 40 nonword fillers were derived from the filler words. All nonwords consisted of orthographically and phonotactically legal letter strings. The lists of verb stimuli were matched $(F \mathrm{~s}<1)$ within the different subsets according to the LEXIQUE 2 database (New et al., 2004) using log-transformed frequencies. Yet, matching between all different subsets, and more particularly between the R-R and the sR-sR subset, was impossible because of language-specific frequency constraints so that subregular verbs were globally less frequent than regular verbs. Within each subset, the stimuli lists were also matched for the number of letters (all $F$ s $<1$ ). The materials of the three subsets and their respective stimuli lists are summarized in Table 4.

The stimuli were presented on an IBM LCD monitor using E-Prime software and RTs were recorded using a
French computer keyboard. Stimuli were randomly displayed to each participant. Each trial consisted in the presentation of a fixation cross $(+)$ in the middle of the computer screen for 1000 msec followed by the stimulus presented in black uppercase letters on a white background, size 18, centered in the same position as the fixation cross. Participants were placed approximately $30 \mathrm{~cm}$ from the computer screen and were instructed to decide as accurately and as quickly as possible whether the letter string was a French word or not. They were told to press the button corresponding to their dominant hand if the stimulus was a real word and the button corresponding to their nondominant hand if the stimulus was not a real word. Stimuli remained on the computer screen until the participant responded. A new trial was initiated $1000 \mathrm{msec}$ after the response. The total duration of the experimental session was approximately $15 \mathrm{~min}$.

\section{RESULTS \\ Experiment 1}

Analyses of variance (ANOVAs) were conducted by subjects (F1) and by items (F2) with the dependent variable "accuracy" and the independent variables "group" (HD, controls) and "category" (irregular verbs, regular verbs, subregular verbs, regular NV, and subregular NV). Results are displayed in Figure 1.

Performance was significantly better for controls than for HD with respectively $98.6 \%( \pm 3.1)$ and $87.9 \%$ $( \pm 16.5)$ correct answers $[F 1(1,28)=63.21, p<.001$; $F 2(1,106)=69.94, p<.001]$. Analyses revealed a category effect $[F 1(4,112)=55.87, p<.001 ; F 2(4,106)=$ $22.07, p<.001]$ and an interaction between group and 
Figure 1. Performance on verb and NV forms in controls and HD patients.

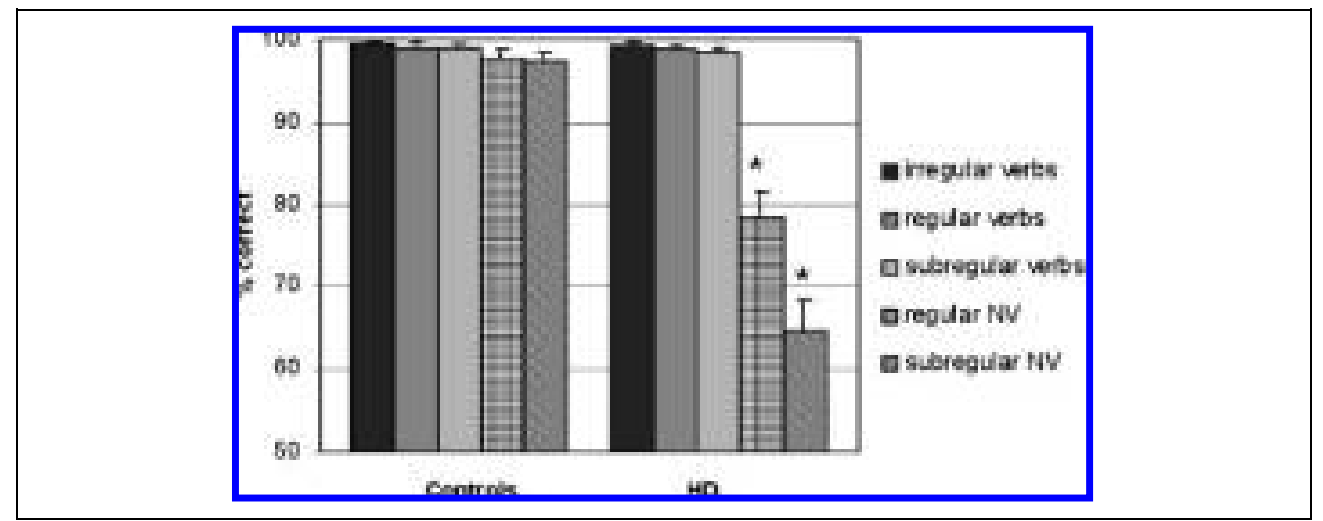

category $[F 1(4,112)=44.83, p<.001 ; F 2(4,106)=$ $29.46, p<.001]$ because controls performed similarly for all verb categories, whereas HD patients did not. Restricted analyses showed that unlike controls, HD patients performed better with irregular verbs than with $\mathrm{NV}$, yielding a Group $\times$ Category interaction $[F 1(1,28)=$ $67.52, p<.001 ; F 2(1,67)=54.63, p<.001]$. Moreover, HD patients performed better with regular NV than with subregular NV, yielding another Group $\times$ Category interaction $[F 1(1,28)=10.65, p=.003 ; F 2(1,40)=4.50$, $p<.04]$. For the other contrasts, both controls and HD had similar performance with regular, subregular, and irregular verbs $[F 1(2,56)=1.21, p>.1 ; F 2<1]$ with no group effect $[F 1<1 ; F 2(1,66)=1.31, p>.1]$ and no Group $\times$ Verb type interaction $[F 1<1 ; F 2<1]$.

Error types were analyzed using ANOVAs with the independent variables "group" (HD, controls) and "error type" (acceptance of overregularizations, subregularizations, double suffixations, aberrant suffixations, and rejection of correct forms). Results are summarized in Table 5. There was a group effect $[F 1(1,28)=63.45$, $p<.001 ; F 2(1,106)=38.31, p<.001]$ and an error-type effect $[F 1(4,112)=18.37, p<.001 ; F 2(4,106)=6.53$, $p<.001]$. Furthermore, the distribution of error types was different for controls and HD patients, yielding a Group $\times$ Error-type interaction $[F 1(4,112)=8.48, p<$ $.001 ; F 2(4,106)=4.15, p=.004]$.

Within NV, two particular contrasts were analyzed. First, because double suffixations, overregularizations, and subregularizations correspond to the use of inadequate rules, they were combined as "rule errors" and compared to aberrant suffixations. Rule errors were more frequent than aberrant suffixations in both controls and HD [respectively $F(1,14)=11.67, p=.004$; $F 2(1,28)=9.66, p=.004$, and $F(1,14)=38.76, p<.001$; $F 2(1,28)=24.70, p<.001]$. Second, because overregularizations and double suffixations have to do with the excessive use of the productive default rule while subregularizations relate to excessive use of subrules, they were analyzed respectively as excessive default rule

Table 5. Percentage of Errors by Types and by Stimulus Category for HD Patients (HD) and Controls (C)

rule errors

\begin{tabular}{|c|c|c|c|c|c|c|c|c|c|c|}
\hline & \multicolumn{2}{|c|}{ Correct } & \multicolumn{2}{|c|}{ Double Suffix } & \multicolumn{2}{|c|}{ Overreg } & \multicolumn{2}{|c|}{ Subreg } & \multicolumn{2}{|c|}{ Aberr. Suffix } \\
\hline & C & $H D$ & C & $H D$ & $C$ & $H D$ & $C$ & $H D$ & C & $H D$ \\
\hline Irregular verbs & 1.1 & 3.3 & 2.2 & 0 & 0 & 0 & 0 & 0 & 0 & 0 \\
\hline Regular verbs & 0 & 0 & 4.4 & 6.7 & & & 1.1 & 1.1 & 0 & 0 \\
\hline Subregular verbs & 0 & 1.1 & 4.4 & 6.7 & 1.1 & 1.1 & & & 0 & 0 \\
\hline Regular NV & 0 & 3.3 & 8.9 & $46.7^{*}$ & & & 3.3 & $27.8^{*}$ & 0 & $21.1^{*}$ \\
\hline Subregular NV & 0 & $7.8^{*}$ & 4.4 & $62.2 *$ & 6.7 & $66.7^{*}$ & & & 0 & $17.8^{*}$ \\
\hline Total & 0.2 & 3.1 & 4.9 & 24.4 & 2.6 & 22.6 & 1.5 & 9.6 & 0 & 7.8 \\
\hline
\end{tabular}

Error types: reject of correct forms (correct), acceptation of double suffixations (double suffix), overregularizations (Overreg), subregularizations (Subreg), and aberrant suffixations (Aberr. suffix). For the comparisons between controls and HD: $* p$ is significant at the .05 level. 
errors and excessive subrule errors. There was no difference in controls between these two error types, whereas in HD, errors were mostly related to excessive use of the default rule, yielding a Group $\times$ Error-type interaction $[F 1(1,28)=7.98, p<.001 ; F 2(1,16)=21.43$, $p<.001]$.

\section{Experiment 2}

ANOVAs were conducted by subjects $(F 1)$ and by items (F2) with RT as the dependent variable. For each participant, incorrect responses, missing data, and extreme RT (less or more than mean $\pm 2 S D$ ) were excluded from the analyses ( $9 \%$ of the data). The analyses of the three experimental subsets were separated because the stimuli were matched within, but not between, subsets. Results are summarized in Figures 2, 3, and 4.

\section{$I-R$ Subset}

The three independent variables were "group" (HD, controls), "verb type" (regulars, irregulars), and "surface frequency" (high and low surface frequency). RTs were slower in HD patients than in controls $[F 1(1,28)=$ $18.14, p<.001 ; F 2(1,27)=132.14, p<.001]$. There was a significant effect of surface frequency and of verb type: RTs were faster with high surface frequency forms than with low surface frequency forms $[F 1(1,28)=101.88$, $p<.001 ; F 2(1,27)=19.44, p<.001]$ and RTs were slower with irregulars than with regulars $[F 1(1,28)=$ $18.37, p<.001 ; F 2(1,27)=6.42, p=.02]$. There was a significant Verb type $\times$ Surface frequency interaction $[F 1(1,28)=23.08, p<.001 ; F 2(1,27)=5.28, p=.03]$ and a triple Group $\times$ Verb type $\times$ Surface frequency interaction $[F 1(1,28)=7.97, p=.009 ; F 2(1,27)=5.57$, $p=.03]$. Restricted analyses showed that controls displayed a surface frequency effect with irregular but not with regular verbs [respectively $F 1(1,14)=74.44$, $p<.001 ; F 2(1,11)=5.65, p=.04$ and $F 1(1,14)=$ $1.93, p>.1 ; F 2<1$ ], whereas HD patients showed a surface frequency effect for both irregular and reg- ular verbs [respectively $F 1(1,14)=20.32, p<.001$; $F 2(1,11)=12.76, p=.004$ and $F 1(1,14)=51.74$, $p<.001 ; F 2(1,16)=13.25, p=.002]$. As surface frequency effects with irregulars reflect mechanisms of lexical access, we determined "lexical efficiency" by calculating the ratio between high- and low-frequency irregulars on average RT per subject ("lexical efficiency" = $\left.\mathrm{RT}_{\text {low-frequency irregulars }} / \mathrm{RT}_{\text {high-frequency irregulars }}\right)$. Likewise, "rule efficiency" was assessed by calculating the ratio between low-frequency regulars and low-frequency irregulars on average $\mathrm{RT}$ per subject ("rule efficiency" = $\mathrm{RT}_{\text {low-frequency irregulars }} / \mathrm{RT}_{\text {low-frequency regulars }}$ ). ANOVAs showed that "lexical efficiency" was similar for controls and for HD patients $[F(1,28)=1.34, p>.1]$, whereas "rule efficiency" was decreased in HD patients as compared to controls $[F(1,28)=13.58, p=.001]$.

\section{$R-R$ Subset}

We defined "group" (HD, controls) and, either "surface frequency" (high, low) or "root frequency" (high, low) as independent variables. HD patients had slower RT than controls $[F 1(1,28)=15.63, p<.001 ; F 2(1,27)=$ $205.78, p<.001]$ and high surface frequency forms elicited faster responses than low surface frequency forms $[F 1(1,28)=15.70, p=.001 ; F 2(1,18)=16.04, p<.001]$. There was a significant Group $\times$ Surface frequency interaction $[F 1(1,28)=16.23, p<.001 ; F 2(1,18)=8.46$, $p=.009$ ] because high and low surface frequency forms elicited similar RT in controls, whereas HD patients displayed slower RT with low than with high surface frequency forms. Finally, controls and HD patients had slower RT with low than with high root frequency regulars $[F 1(1,28)=80.28, p<.001 ; F 2(1,18)=23.82$, $p<.001]$ with no Group $\times$ Root frequency interaction $[F 1<1, F 2<1]$.

\section{$s R-s R$ Subset}

As in the R-R subset, we defined "group" (HD, controls) and, either "surface frequency" (high, low) or "root fre-
Figure 2. Experiment 2, I-R subset. Reaction times in controls and HD patients with regular and irregular verbs while varying surface frequencies.

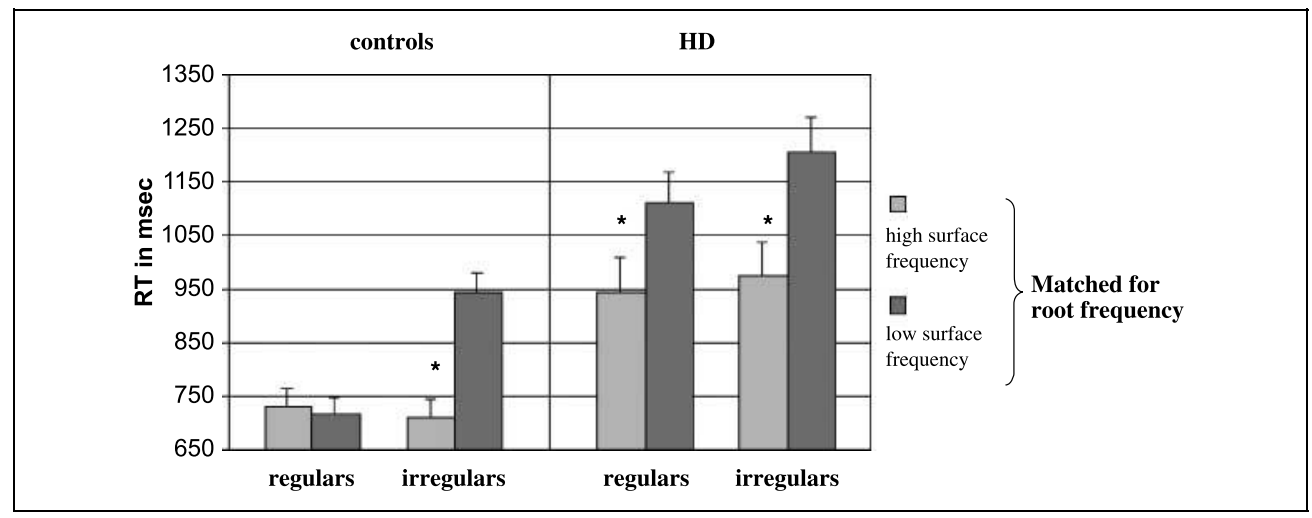


Figure 3. Experiment 2, R-R subset. Reaction times with regular verb forms varying surface and root frequencies.

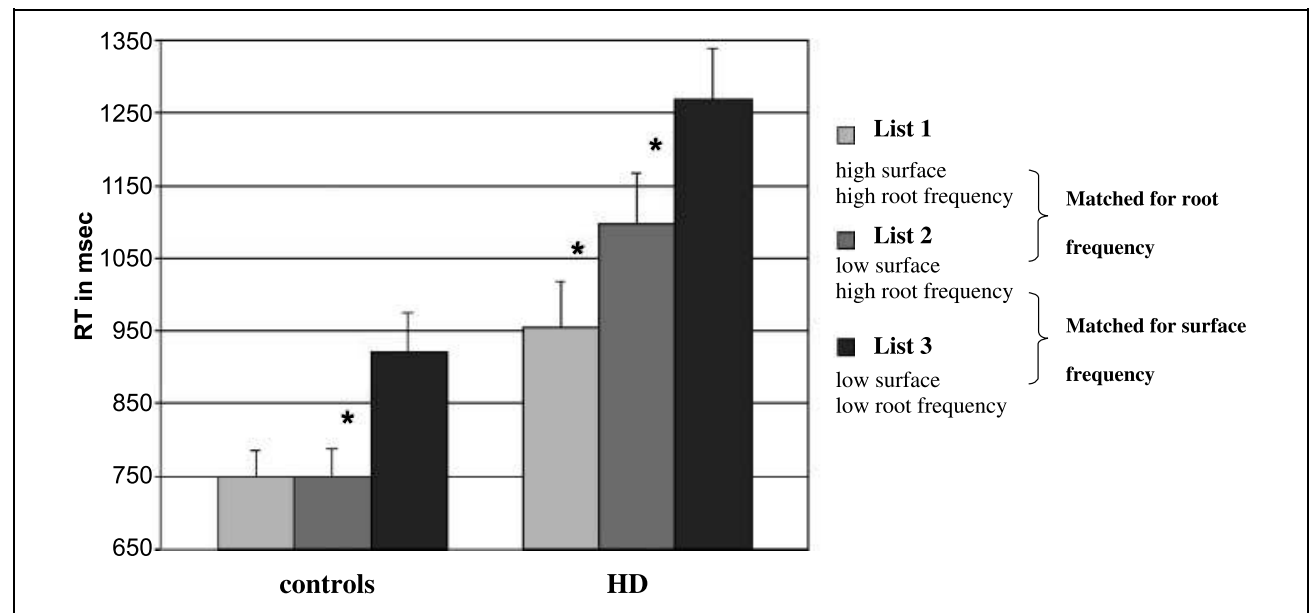

quency" (high, low) as independent variables. RTs were slower in HD patients than in controls $[F 1(1,28)=14.62$, $p=.001 ; F 2(1,23)=139.37, p<.001]$. There was no significant surface frequency effect $[F 1<1 ; F 2<1]$, or a Group $\times$ Surface frequency interaction $[F 1<1 ; F 2<$ $1]$. In contrast, there was a main root frequency effect $[F 1(1,28)=105.30, p<.001 ; F 2(1,15)=27.14, p<.001]$. This effect was significant for both controls $[F 1(1,14)=$ 71.95, $p<.001 ; F 2(1,15)=34.59, p<.001]$ and HD patients $[F 1(1,14)=34.21, p<.0001 ; F 2(1,15)=7.23$, $p=.02]$, whereas a Group $\times$ Root frequency interaction indicates that its magnitude was greater for controls $[F 1(1,28)=7.75, p=.01 ; F 2(1,15)=6.04, p=.03]$.

Analyses on performance accuracy were conducted similar to RT. Results are summarized in Table 6.

\section{I-R Subset}

Performance in controls $(97.2 \% \pm 7.2$ correct) and in HD patients $(94.8 \% \pm 10.2$ correct) was similar in the bysubject, but not in the by-item, analysis $[F 1(1,28)=1.64$, $p>.1 ; F 2(1,27) 5.34, p<.03]$. Performance was better with regulars than with irregulars $[F 1(1,28)=10.77$, $p=.003 ; F 2(1,27)=5.00, p=.03]$ without any surface frequency effect $[F 1(1,28)=1.59, p>.1 ; F 2(1,27)=$ $1.23, p>1$ ] or a Verb type $\times$ Surface frequency interaction $[F 1(1,28)=1.63, p>.1 ; F 2(1,27)=1.22, p>.1]$. The interactions with the variable group (Verb type $\times$ Group, Surface frequency $\times$ Group, Verb type $\times$ Surface frequency $\times$ Group) did not reach statistical significance $($ all $F$ S $<1)$

\section{$R-R$ Subset}

Performance for controls $(97.3 \% \pm 6.2$ correct) and HD patients $(95.0 \% \pm 9.6$ correct) was similar $[F 1(1,28)=$ $2.97, p>.1 ; F 2(1,27)=3.56, p=.07]$. There was no surface frequency effect $[F 1(1,28)=2.32, p>.1 ; F 2(1,18)=$ $4.25, p=.054]$ and no Group $\times$ Surface frequency in teraction $[F 1(1,28)=1.05, p>.1 ; F 2(1,18)=2.45, p>$ .1]. High root frequency forms yielded better performance than low-frequency forms $[F 1(1,28)=5.76, p=.02$; $F 2(1,18)=8.95, p=.008]$, with no Group $\times$ Root frequency interaction $[F 1<1, F 2<1]$.
Figure 4. Experiment 2, sR-sR subset. Reaction times with subregular verb forms varying surface and root frequencies.

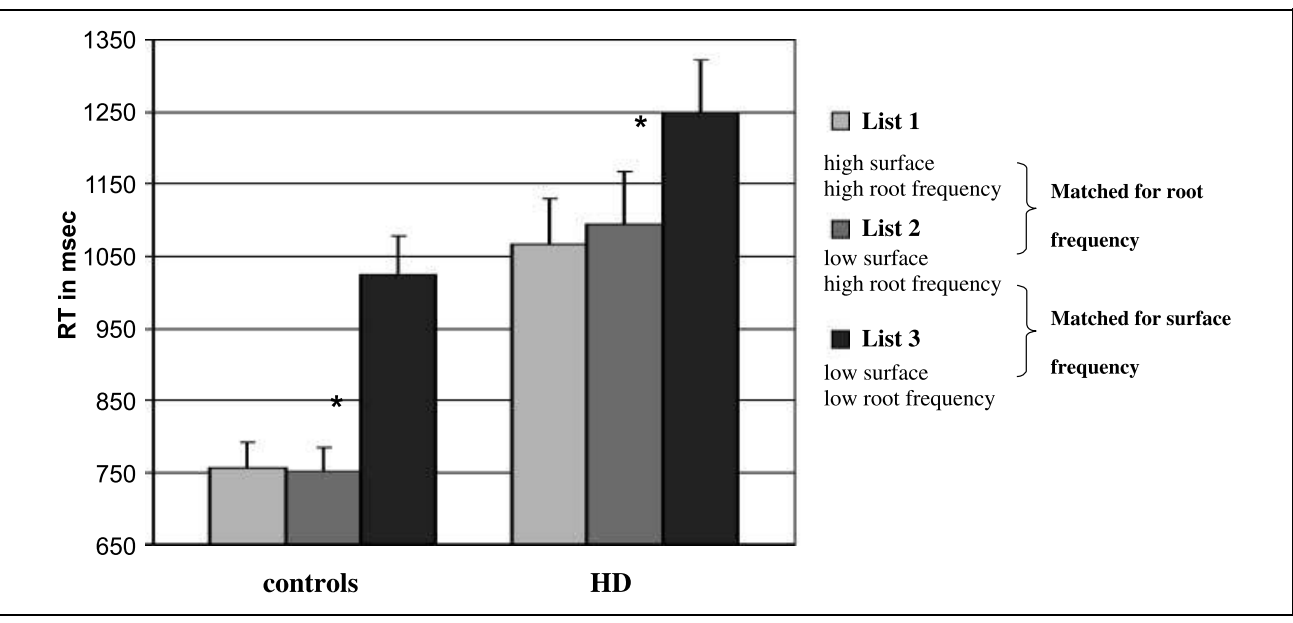


Table 6. Mean Percentage of Correct Responses and $S D$ for HD Patients (HD) and Controls in the Different Subsets of Experiment 2

\begin{tabular}{llccc}
\hline Subset & Verb Type & List & Controls & HD \\
\hline I-R & Regulars & List 1 & $100 \pm 0$ & $96.8 \pm 5.5$ \\
& & List 2 & $100 \pm 0$ & $96.8 \pm 6.9$ \\
& \multirow{3}{*}{ Irregulars } & List 3 & $95.6 \pm 9.9$ & $95.3 \pm 10.2$ \\
& & List 4 & $93.2 \pm 9.3$ & $90.3 \pm 15.1$ \\
R-R & Regulars & List 1 & $100 \pm 0$ & $99.2 \pm 3.2$ \\
& & List 2 & $99.3 \pm 2.6$ & $95.8 \pm 9$ \\
& & List 3 & $92.7 \pm 8.8$ & $90.2 \pm 12.5$ \\
sR-sR & Subregulars & List 1 & $98.5 \pm 3.9$ & $100 \pm 0$ \\
& & List 2 & $97 \pm 6.6$ & $96.5 \pm 7.7$ \\
& & List 3 & $88 \pm 14.5$ & $82.3 \pm 17$ \\
\hline
\end{tabular}

\section{sR-sR Subset}

Performance were similar in controls $(94.5 \% \pm 10.4$ correct) and in HD patients $[92.9 \% \pm 13.1$ correct; $F 1<1$; $F 2(1,23)=1.46, p>.1]$. There was no surface frequency effect $[F 1(1,28)=2.92, p>.1 ; F 2(1,16)=2.93, p>$ .1] and no Group $\times$ Surface frequency interaction $[F 1<$ $1 ; F 2(1,16)=2.33, p>.1]$. High root frequency forms yielded better performance than low-frequency forms $[F 1(1,28)=12.56, p=.001 ; F 2(1,15)=9.70, p=.007]$, with no Group $\times$ Root frequency interaction $[F 1<1$; $F 2(1,15)=1.12, p>.1]$.

\section{Correlation Analyses}

Correlation analyses were performed with the clinical data from the $15 \mathrm{HD}$ patients except bicaudate ratios $(n=10)$. Rule processing was assessed with the experimental conditions that yielded the strongest difference

Table 7. Correlation Analyses in HD Patients

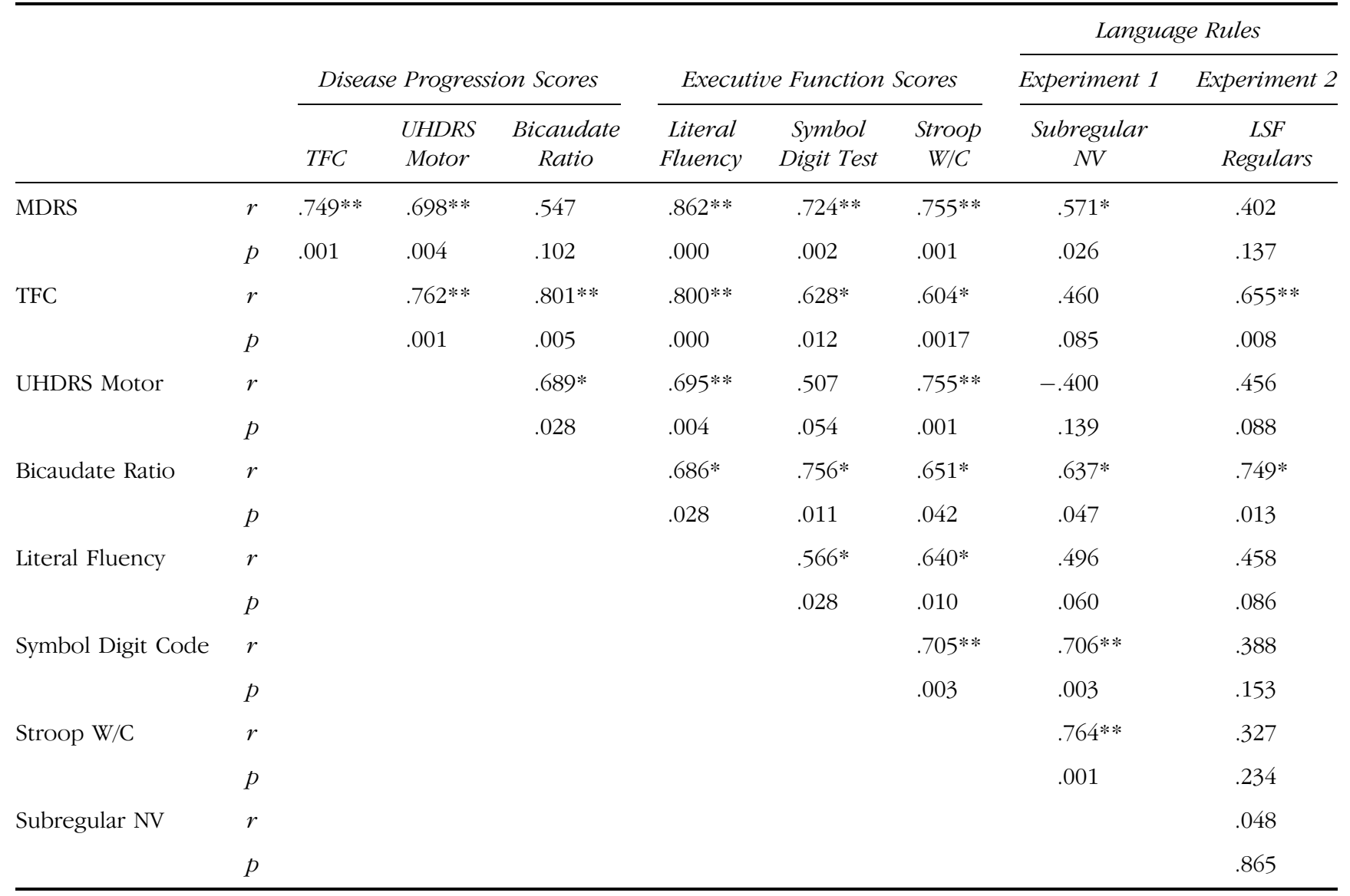

Correlation analyses included all $15 \mathrm{HD}$ patients except for bicaudate ratios $(n=10) . r=$ correlation coefficient; TFC $=$ total functional capacity; UHDRS Motor = motor scores; Literal Fluency = literal fluency "P" and "V" in 2 min; Stroop W/C = word-color subpart of the Stroop task; LSF regulars $=$ low surface frequency regulars of the I-R subset (Experiment 2).

*p is significant at the .05 level (two-tailed).

$* * p$ is significant at the .01 level (two-tailed). 
between HD patients and controls: performance with subregular NV (Experiment 1) and RT with low surface frequency regulars of the I-R subset (Experiment 2). Results are detailed in Table 7.

Disease progression scores (TFC, motor scores, and bicaudate ratios) and global intellectual capacities (MDRS) correlated with one another (except bicaudate ratio and MDRS). Executive function scores correlated with all of these scores except with the Symbol Digit Code and motor scores. Performance with subregular NV correlated with executive functions (except literal fluency) and MDRS, but not with TFC or with motor scores. Conversely, RT with low surface frequency regulars correlated only with TFC, but not with executive functions scores or with MDRS or motor scores. Bicaudate ratios correlated significantly with rule application on both subregular NV and low surface frequency regulars.

\section{DISCUSSION}

In this study, we investigated the role of the striatum in the perceptive modality of morphological processing by assessing HD patients in an early disease stage. Participants were assessed in explicit and implicit tasks, involving respectively grammatical judgment and lexical decision on conjugated verb and NV forms. Under the assumption that HD patients are selectively impaired on rules, we expected them to fail on $\mathrm{NV}$ and to avoid rule application with frequent regular and subregular verbs by accessing them flawlessly in the mental lexicon like irregular forms. Furthermore, under the assumption that low-frequency regulars are necessarily submitted to rule application (Schreuder \& Baayen, 1995), we predicted that HD patients would have difficulties in processing low-frequency regular and subregular verb forms.

Experiment 1 showed that HD patients had flawless performance with frequent regular, subregular, and irregular verbs, whereas they were impaired with $\mathrm{NV}$, in particular, with subregular NV. Errors with NV mainly resulted from overapplication of the productive default rule. Experiment 2, which used high- and low-frequency verbs, showed that HD patients and controls have better performance with regulars than irregulars independently from their respective surface frequency. Yet, it appears that accuracy measures are not sensitive enough to provide evidence for impaired rule application in lowfrequency forms of decomposable verbs. However, the more sensitive RT data revealed that HD behave abnormally with regular verbs. In controls, RT with regular and subregular verbs depended on root frequencies, whereas they depended on surface frequencies for irregulars. By contrast, in HD patients, RT with regular verbs depended on root frequencies only for low surface frequency forms (mean surface frequency 0.2 per million), whereas they depended on surface frequencies for high surface frequency forms (mean surface frequency 1.6 per million). This confirms that HD patients avoid rule application in frequent regular forms, accessing them in the lexicon, but still apply rules to infrequent forms. Comparing RT with low-frequency regulars (rule application) and irregulars (lexical processes) showed, however, that rule application with infrequent regulars is less efficient than in controls. The RT pattern with irregular verb forms was normal in HD. Moreover, surface frequency effects for irregular forms have the same magnitude in controls and HD patients confirming that "lexical efficiency" is spared in these patients. Finally, the RT pattern with subregular verbs, which were globally less frequent than regulars (mean surface frequency 0.1 per million), was similar to controls, suggesting that infrequent forms of decomposable verbs are necessarily submitted to rule computation.

Together, these data support the claim that HD patients have intact lexical access but are hampered in rule application. The analysis of error types with NV furthermore suggests that rule disorders involve two components, namely, reduction of subrule computation and excessive release of the default rule. This rule imbalance is broadly consistent with several studies that assessed HD patients during speech production. Ullman, Corkin, et al. (1997) observed excessive suffixation of regular and irregular verbs (e.g., dig-ed, look-ed-ed), and Teichmann et al. (2005) reported deficient conjugation of subregular NV that resulted from overregularizations. However, the results of production studies, which are confounded by striatal generated articulation disorders, yielded conflicting views about the striatumrule correlate: Ullman, Corkin, et al. (1997) claimed striatal involvement in the application of the default rule, Teichmann et al. (2005) restricted this view to subrules, whereas Longworth et al. (2005) fully rejected the striatum-rule hypothesis. Our investigations in the domain of language perception clarify this blurred picture and show that striatal-damaged patients are genuinely impaired on morphological processes. In particular, impairment on both combination of morphemes (production) and their decomposition (perception) underscores that disorders are tied to the same underlying core operation, namely, rule computation. The striatum, we argue, is specifically involved in this core operation which breaks down progressively when striatal damage occurs, first hampering poorly automatized subrule computations and subsequently extending to the more robust default rule. Moreover, using an implicit manipulation task, we showed that rule disorders can hardly be attributed to the failure of intentional response strategies but rather follow from a genuine damage to implicit language computations. In sum, our results substantiate the striatum-rule hypothesis (Ullman, 2001), generalizing arguments to language perception, and by extending evidence to implicit aspects of language processing.

Supporting evidence for striatal involvement in implicit rule processing has also been provided in the domain of artificial grammar learning. In an fMRI study, 
Lieberman, Chang, Chiao, Bookheimer, and Knowlton (2004) showed that striatal activation occurs when adults abstract rules from letter strings even though they have little conscious insight in the inherent rule structure. Yet, our results seem to be at odds with morphological priming data that were obtained using striatal-damaged patients (Longworth et al., 2005). The authors showed that regular and irregular past-tense forms equally prime their respective base forms, suggesting that implicit rule application is preserved in HD patients. However, these results do not necessarily contradict our findings. First, it was not reported whether priming effects with regular verbs yield the same magnitude in controls as in HD patients. Second, given that priming was observed in both irregular and regular pairs, it is difficult to know whether frequent regulars are lexically accessed like irregulars and whether infrequent regulars are still decomposed as shown by the present research. Third, given that all the regular and irregular pairs of the Longworth study were highly semantically as well as morphologically related, it remains unclear whether priming effects for regulars are due to morphological rule application or merely to semantic effects. Finally, the small number of HD patients $(n=7)$ and the lack of control for evolution stage may have masked any effect (the authors did not provide disease stage of their patients but their independence scale rating corresponds overall to Stages II and III).

Despite this seeming discrepancy between the previous priming results and the frequency effects of the present research, it should be noted that there is no evidence for striatal involvement in lexical processes. Intriguingly, this assumption (e.g., Wallesch \& Papagno, 1988) was mainly based on patient studies, which used explicit tasks such as "verbal fluency" (e.g., Butters et al., 1986) or "object naming" (Frank, McDade, \& Scott, 1996) that rely heavily on executive components such as intentional word recovery. Thus, we suggest that the striatum is not involved in lexical processes as such but that it operates in a non-language-specific fashion through intentional research in the lexicon. This mechanism could also account for other lexico-semantic failures such as the production of semantic paraphasias, which were reported in patients that have subcortical lesions (Damasio, Damasio, Rizzo, Varney, \& Gersh, 1982).

\section{A More General Rule Function of the Striatum}

Our study substantiates the fundamental role of the striatum in implicit and, more particularly, in languagespecific rule computations. Yet, we propose that the striatal rule function is a more general faculty that cuts across both implicit processes and intentional rule manipulation. Indeed, judgment of $\mathrm{NV}$ forms as tested in Experiment 1 may basically relate to strategic detection of analogies with existing verbs and the conscious generalization of suffix patterns to novel linguistic ma- terial. Ashby and Waldron (1999) have claimed that the kind of intentional manipulation of regularities is part of executive functions involving a fronto-striatal network. According to this view, it has been shown that striataldamaged patients are impaired on diverse executive function tasks that require explicit manipulation of rulelinked instances like in the Wisconsin Card Sorting Test (e.g., Monchi et al., 2004). Furthermore, brain imaging data of healthy volunteers from a task similar to the Wisconsin Card Sorting Test showed activation in prefrontal areas and in the striatum (Rao et al., 1997). The correlation analyses we ran bear upon this double explicit/implicit rule function of the striatum. We found that performance with explicit (Experiment 1) and implicit (Experiment 2) rule application did not correlate one with each other, whereas both correlated to measures of striatal atrophy. Furthermore, only performance on the explicit task correlated with executive function scores. Taken together, these results may suggest that the striatum encompasses distinct computational circuits that are partly specialized for implicit rule processes, such as those required for modular language operations, whereas others are involved in intentional rule manipulation via their link to prefrontal executive areas (see also Seger \& Cincotta, 2002).

\section{Novel Elements for Language Models}

Current language models can roughly be divided into two concurring views comprising dual lexicon/rule accounts (e.g., Pinker, 1991) and connectionist singlesystem models (e.g., Rumelhart \& McClelland, 1986). The present research adds into a long series of studies, which show that behavioral data of healthy adults and of brain-damaged patients can dissociate the language faculty into two components. First, our results suggest that lexical mechanisms apply to monomorphemic representations such as irregular forms and roots, whereas combinatorial rules apply to complex words such as regular or subregular forms (see also Clahsen et al., 1997; Schreuder \& Baayen, 1995; Taft, 1979). Second, we showed that both language components can be dissociated in striatal-damaged patients. Additional evidence for neural dissociations has also been provided with vascular patients (Ullman et al., 2005; Tyler et al., 2002; Marslen-Wilson \& Tyler, 1997) and with healthy volunteers using functional imagery (Beretta et al., 2003; Ullman, Bergida, et al., 1997; Jaeger et al., 1996) and event-related potentials (Münte, Say, Clahsen, Schiltz, \& Kutas, 1999; Gross, Say, Kleingers, Clahsen, \& Münte, 1998; Penke et al., 1997). The combined data from these different methodologies and across different languages underscore a fundamental duality in the functional and anatomical organization of language. However, although our results seem to be at odds with classical single mechanism accounts (Rumelheart \& McClelland, 1986), such limits might not hold for more recent connectionist 
models (see, e.g., Joanisse \& Seidenberg, 1999). Indeed, these models have shown a certain ability to account for functional and anatomical dissociations between regulars and irregulars by assuming that these two verb classes differ not with respect to morphological rule/ lexicon parameters but in their phonological and semantic dimensions. According to these models, the conjugation of regular verbs and especially of novel verbs is more demanding on phonological processing, whereas irregular verbs depend more on semantic specifications. Thus, according to single-system accounts, HD patients would be impaired on phonological abilities but would preserve their semantic capacities. Further studies will have to investigate this issue by clarifying whether the striatum impacts phonological rather than semantic or morphological processing. In brief, the single versus double mechanism debate still remains open (see, e.g., Pinker \& Ullman, 2003; Marslen-Wilson \& Tyler, 2003; McClelland \& Patterson, 2002, 2003) and calls for neuropsychological research that systematically controls for the different dimensions of word processing, including morphological as well as phonological/orthographic and semantic factors.

Yet, the current study showed dissociations not only between regular and irregular verbs but also within regular verbs. Assuming a double mechanism view, this kind of dissociation contributes to clarify some controversy that persists within rule/lexicon accounts referring to whether regular forms are necessarily subjected to rootsuffix computation or whether, in addition, they are directly accessible in the mental lexicon. So-called full parsing models (Pinker, 1991) defend the former view, whereas dual route models state that regular forms may be stored in two lexical formats comprising a decomposed morphemic format and a full-form representation (Schreuder \& Baayen, 1995). Our results clearly support the latter account showing that HD patients readily recover high-frequency forms from the mental lexicon while they still decompose low-frequency forms to some extent. They also support the premise that the human language faculty is designed as a redundant system for reasons that have plausible functional accounts such as compensation for computational damage (see Pinker \& Jackendoff, 2005). Yet, in the case of inflectional morphology, the lexical "back-up option" seems to be restricted to frequent regular verb forms presumably because infrequent forms are merely stored in a decomposed format (see Meunier \& Segui, 1999; Shreuder \& Baayen, 1995; Caramazza, Laudanna, \& Romani, 1988). Thus, representational redundancy is not exhaustive but it nonetheless allows to compensate for rule damage in language contexts that are most frequently encountered.

\section{Conclusion}

Our research provides evidence that substantiates striatal involvement in rule computation and supports lex- icon/rule models in their dual-route perspective. We showed that the rule function of the striatum is not limited to speech production but crucially extends to perceptive aspects of language processing. We also argue that the striatum operates at an implicit level that pertains to genuine language processes. Yet, we assume that the striatum has a more generic role in rule processing that applies beyond modular language rules to intentional extraction of regularities.

One may speculate that striatal structures are implicated in the dynamic processes that comprise intentional rule extraction on the one hand and subsequent automatization of rule application on the other. Indeed, language grammar is a domain where rule application is broadly automated, allowing for effortless conjugation and construction of phrasal structures. According to this view, the striatum was also claimed to be involved in other grammatical domains such as syntax. Several studies using functional imagery with healthy volunteers have shown that the detection of syntactic errors in sentences leads to activation of striatal structures including the caudate nucleus (Moro et al., 2001) and the putamen (Friederici et al., 2003). Likewise, investigation of syntactic capacities in HD has evidenced that comprehension of noncanonical sentences that depend on the application of syntactic derivation rules is impaired (Teichmann et al., 2005). However, preserved performance with canonical sentences suggests that knowledge about word order applies productively to new phrasal situations (Teichmann et al., 2005). Perhaps, the theory about striatal involvement in implicit rule application could be refined by constraining it to recursive rules such as morphological suffixation or syntactic derivation rules. Further research is needed to evaluate this more refined distinction in different domains of linguistic and nonlinguistic processing.

\section{Acknowledgments}

This work was conducted with the help of an Avenir grant (2001) allocated to A. C. Bachoud-Lévi by the INSERM and an Assistant Hospitalier de Recherche grant (AHR AP-HP/INSERM) to Marc Teichmann. We thank Marie-Françoise Boissé for assessing MDRS scores and cognitive scales of the UHDRS and Guillaume Dolbeau and Amandine Rialland for transmitting the data. Furthermore, we thank the Center of Clinical Investigations (CIC). We are grateful to Pierre Brugières for RMI acquisitions and to the Huntington French Speaking Group (Réseau Huntington de Langue Française) who supports this work. We also thank Susana Franck for her corrections of the manuscript.

Reprint requests should be sent to Marc Teichmann, Equipe Avenir, INSERM U421/Faculté de Médecine Paris XII, 8 rue du Général Sarrail, 94010 Créteil, France, or via e-mail: marcteichmann@hotmail.com.

\section{Note}

1. Irregular forms are monomorphemic representations that do not contain roots. For reasons of exactitude, the term root 
frequency should therefore be substituted in irregulars by the term cumulative frequency. Yet, for the sake of simplicity, the term root frequency will be used here for both regular and irregular verbs.

\section{REFERENCES}

Ashby, F. G., \& Waldron, E. M. (1999). On the nature of implicit categorization. Psychonomic Bulletin and Review, 6, 363-378.

Balota, D. (1994). Visual word recognition. The journey from features to meaning. In M. Gernsbacher (Ed.), Handbook of psycholinguistics. San Diego, CA: Academic Press.

Beretta, A., Campbell, C., Carr, T. H., Huang, J., Schmitt, L. M., Christianson, K., \& Cao, Y. (2003). An ER-fMRI investigation of morphological inflection in German reveals that the brain makes a distinction between regular and irregular forms. Brain and Language, 85, 67-92.

Bertram, R., Schreuder, R., \& Baayen, R. H. (2000). The balance of storing and computation in morphological processing. The role of word formation type, affixal homonymy, and productivity. Iournal of Experimental Psychology: Learning. Memory and Cognition, 26, 489-511.

Brown, L. L., Schneider, J. S., \& Lidsky, I. L. (1997). Sensory and cognitive functions of the basal ganglia. Current Opinion in Neurobiology, 7, 157-163.

Butters, N., Wolfe, J., Granholm, E., \& Martone, M. (1986). An assessment of verbal recall, recognition and fluency abilities in patients with Huntington's disease. Cortex, 22, $11-32$.

Caramazza, A., Laudanna, A., \& Romani, C. (1988). Lexical access and inflectional morphology. Cognition, 28, 297-332.

Cardebat, D., Doyon B., Puel, M., Goulet, P., \& Joanette, Y. (1990). Formal and semantic lexical evocation in normal subjects. Performance and dynamics of production as a function of sex, age and educational level. Acta Neurologica Belgica, 90, 207-217.

Chomsky, N. (1965). Aspects of the theory of syntax. Cambridge: MIT Press.

Clahsen, H. (1999). Lexical entries and rules of language: A multidisciplinary study of German inflection. Behavioral and Brain Sciences, 22, 991-1013.

Clahsen, H., Eisenbeiss, S., \& Sonnenstuhl, I. (1997). Morphological structure and the processing of inflected words. Theoretical Linguistics, 23, 201-249.

Copland, D. (2003). The basal ganglia and semantic engagement: Potential insights from semantic priming in individuals with subcortical vascular lesions, Parkinson's disease, and cortical lesions. Journal of the International Neuropsychological Society, 9, 1041-1052.

Crosson, B. (1985). Subcortical functions in language: A working model. Brain and Language, 25, 257-292.

Damasio, A. R., Damasio, H., Rizzo, M., Varney, N., \& Gersh, F. (1982). Aphasia with non-hemorrhagic lesions in the basal ganglia and internal capsule. Archives of Neurology, 39, 15-24.

Frank, E. M., McDade, H. L., \& Scott, W. K. (1996). Naming in dementia secondary to Parkinson's, Huntington's, and Alzheimer's diseases. Journal of Communication Disorders, 29, 183-197.

Friederici, A., \& Kotz, S. A. (2003). The brain basis of syntactic processes: Functional imaging and lesion studies. Neuroimage, 20, 8-17.

Friederici, A., Ruschemeyer, S. A., Hahne, A., \& Fiebach, C. J. (2003). The role of left inferior frontal and superior temporal cortex in sentence comprehension: Localising syntactic and semantic processes. Cerebral Cortex, 13, 70-77.

Golden, C. J. (1978). Stroop color and word test. Chicago, Illinois: Stoelting Company.

Gross, M., Say, T., Kleingers, M., Clahsen, H., \& Münte, T. F. (1998). Human brain potentials to violations in morphologically complex Italian words. Neuroscience Letters, 30, 83-86.

Huntington Study Group. (1996). Unified Huntington's Disease Rating Scale: Reliability and consistency. Movement Disorders, 11, 136-142.

Illes, J. (1989). Neurolinguistic features of spontaneous language production dissociate three forms of neurodegenerative disease: Alzheimer's, Huntington's, and Parkinson's. Brain and Language, 37, 628-642.

Jaeger, J., Lockwood, A. H., Kemmerer, D. L., Van Valin, R. D., Murphy, B. W., \& Khalak, H. G. (1996). A positron emission tomographic study of regular and irregular verb morphology in English. Language, 72, 451-497.

Joanisse, M. F., \& Seidenberg, M. S. (1999). Impairments in verb morphology following brain injury: A connectionist model. Proceedings of the National Academv of Sciences. U.S.A., 96, 7592-7597.

Kuhl, D. E., Phelps, M. E., Markham, C. H., Metter, E. J., Riege, W. H., \& Winter, J. (1982). Cerebral metabolism and atrophy in Huntington's disease determined by 18FDG and computed tomographic scan. Annals of Neurologv, 12, 425-434.

Kumral, E., Evyapan, D., \& Balkir, K. (1999). Acute caudate vascular lesions. Stroke, 30, 100-108.

Lieberman, M. D., Chang, G. Y., Chiao, J., Bookheimer, S. Y., \& Knowlton, B. J. (2004). An event-related fMRI study of artificial grammar learning in a balanced chunk strength design. Journal of Cognitive Neuroscience, 16, 427-438.

Lieberman, P. (2001). Human language and our reptilian brain. The subcortical bases of speech, syntax, and thought. Perspectives in Biology and Medicine, 44, 32-51.

Longworth, C. E., Keenan, S. E., Barker, R. A., Marslen-Wilson, W. D., \& Tyler, L. K. (2005). The basal ganglia and rule-governed language use: Evidence from vascular and degenerative conditions. Brain, 128, 584-596.

MacKay, D. (1978). Derivational rules and the internal lexicon. Journal of Verbal Learning and Verbal Behaviour. $17,61-71$.

Marslen-Wilson, W. D., \& Tyler, L. K. (1997). Dissociating types of mental computation. Nature, 387, 592-594.

Marslen-Wilson, W. D., \& Tyler, L. K. (2003). Capturing underlying differentiation in the human language system. Trends in Cognitive Sciences, 7, 62-63.

Mattis, S. (1976). Mental status examination for organic mental syndrome in elderly patients. In L. Bellak \& T. B. Karasu (Eds.), Geriatric psychiatry. New York: Grune \& Straton.

McClelland, J. L., \& Patterson, K. (2002). Rules or connections in past-tense inflections: What does the evidence rule out? Trends in Cognitive Sciences, 6, 465-472.

McClelland, J. L., \& Patterson, K. (2003). Differentiation and integration in human language. Trends in Cognitive Sciences, 7, 63-64.

Meunier, F., \& Segui, J. (1999). Morphological priming effect: The role of surface frequency. Brain and Language, 68, 54-60.

Monchi, O., Petrides, M., Doyon, J., Postuma, R. B., Worsley, K., \& Dagher, A. (2004). Neural bases of set shifting deficits in Parkinson's disease. Journal of Neuroscience, 21, $702-710$.

Moro, A., Tettamanti, M., Perani, D., Donati, C., Cappa, S. F., \& Fazio, F. (2001). Syntax and the brain: Disentangling grammar by selective anomalies. Neuroimage, 13, 110-118. 
Münte, T., Say, T., Clahsen, H., Schiltz, K., \& Kutas, M. (1999). Decomposition of morphologically complex words in English: Evidence from event-related brain potentials. Cognitive Brain Research, 7, 241-253.

New, B., Pallier, C., Brysbaert, M., \& Ferrand, L. (2004). Lexique 2: A new French lexical database. Behavior Research Methods, Instruments, \& Computers, 36, 516-524.

Ni, W., Constable, R. T., Mencl, W. E., Pugh, K. R., Fulbright, R. K., Shaywitz, S. E., Shaywitz, B. A., Gore, J. C., \& Shankweiler, D. (2000). An event-related neuroimaging study distinguishing form and content in sentence processing. Journal of Cognitive Neuroscience, 12, 120-133.

Penke, M., Weyerts, H., Gross, M., Zander, E., Münte, T. F., \& Clahsen, H. (1997). How the brain processes complex words: An event-related potential study of German verb inflections. Brain Research, Cognitive Brain Research, 6, 37-52.

Peschanski, M., Cesaro, P., \& Hantraye, P. (1995). Rationale for intrastriatal grafting of striatal neuroblasts in patients with Huntington's disease. Neuroscience, 68 , 273-285.

Pinker, S. (1991). Rules of language. Science, 253, 530-535.

Pinker, S. (1999). Words and rules: The ingredients of language (1st ed.). New York: Basic Books.

Pinker, S., \& Jackendoff, R. (2005). The faculty of language: What's special about it? Cognition, 95, 201-236.

Pinker, S., \& Ullman, M. (2002). The past and future of the past tense. Trends in Cognitive Sciences, 6 , 456-463.

Rao, S. M., Bobholz, J. A., Hammeke, T. A., Rosen, A. C., Woodley, S. J., Cunningham, J. M., Cox, R. W., Stein, E. A., \& Binder, J. R. (1997). Functional MRI evidence for subcortical participation in conceptual reasoning skills. NeuroReport, 27, 1987-1993.

Rumelhart, D., \& McClelland, J. (1986). On learning the past tenses of English verbs: Implicit rules or parallel distributed processing? In J. McClelland, D. Rumelhart, \& the PDP Research Group (Eds.), Parallel distributed processing: $E$ (pp. 216-271). Cambridge: MIT Press.

Schreuder, R., \& Baayen, H. (1995). Modelling morphological processing. In L. Feldman (Eds.), Morphological aspects of language processing (pp. 131-154). Hillsdale, NJ: Erlbaum.

Seger, C. A., \& Cincotta, C. M. (2002). Striatal activity in concept learning. Cognitive, Affective, and Behavioral Neuroscience, 2, 149-161.

Shoulson, I. (1981). Huntington disease: Functional capacities in patients treated with neuroleptic and antidepressant drugs. Neurology, 31, 1333-1335.
Smith, S., Butters, N., White, R., Lyon, L., \& Granholm, E. (1988). Priming semantic relations in patients with Huntington's disease. Brain and Language, 33, 27-40.

Starkstein, S. E., Folstein, S. E., Brandt, J., Pearlson, G. D., McDonnell, A., \& Folstein, M. (1989). Brain atrophy in Huntington's disease. A CT-scan study. Neuroradiology, 31, 156-159.

Taft, M. (1979). Recognition of affixed words and the word frequency effect. Memory \& Cognition, 7, 263-272.

Teichmann, M., Dupoux, E., Kouider, S., Brugières, P., Boissé, M. F., Baudic, S., Cesaro, P., Peschanski, M., \& Bachoud-Lévi, A. C. (2005). The role of the striatum in rule application. The model of Huntington's disease at early stage. Brain, 128, 1155-1167.

Tettamanti, M., Moro, A., Messa, C., Moresco, R. M., Rizzo, G., Carpinelli, A., Matarrese, M., Fazio, F., \& Perani, D. (2005). Basal ganglia and language: Phonology modulates dopaminergic release. NeuroReport, 15;16, 397-401.

Tyler, L., DeMornay-Davies, P., Anokhina, R., Longworth, C., Randall, B., \& Marslen-Wilson, W. D. (2002). Dissociations in processing past tense morphology: Neuropathology and behavioral studies. Journal of Cognitive Neuroscience. 14, 79-94.

Ullman, M. T. (2001). A neurocognitive perspective on language: The declarative/procedural model. Nature Reviews Neuroscience, 2, 717-726.

Ullman, M. T., Bergida, R., \& O'Craven, K. (1997). Distinct fMRI activation patterns for regular and irregular past tense. Neuroimage, 5, S549.

Ullman, M. T., Corkin, S., Coppola, M., Hickok, G., Growdon, J. H., Koroshetz, W. J., \& Pinker, S. (1997). A neural dissociation within language: Evidence that the mental dictionary is part of declarative memory, and that grammatical rules are processed by the procedural system. Journal of Cognitive Neuroscience, 9, 266-276.

Ullman, M. T., Pancheva, R., Love, T., Yee, E., Swinney, D., \& Hickok, G. (2005). Neural correlates of lexicon and grammar: Evidence from the production, reading, and judgment of inflection in aphasia. Brain and Language. 93, 185-238.

Vonsattel, J. P., Myers, R. H., Stevens T. J., Ferrante, R. J., Bird, E. D., \& Richardson, E. P., Jr. (1985). Neuropathological classification of Huntington's disease. Journal of Neuropathology and Experimental Neurology, 44, 559-577.

Wallesch, C. W., \& Papagno, C. (1988). Subcortical aphasia. In F. C. Rose, R. Whurr, \& M. Wyke (Eds.), Aphasia (pp. 256-287). London: Whurr Publishers.

Wechsler, D. (1981). Manual for the Wechsler Adult Intelligence Scale—Revised. New York: Psychological Corporation. 